\section{CIRCULAÇÕES, DRAMÁTICAS, EFICÁCIAS DA ATIVIDADE INDUSTRIOSA}

\author{
CIRCULATIONS, "DRAMATICS", EFFICACIES \\ OF THE INDUSTRIOUS ACTIVITY
}

Yves Schwartz ${ }^{1}$

Resumo $\mathrm{O}$ artigo trata da relação entre uma certa abordagem do trabalho (como "atividade industriosa") e o manejo dos coeficientes essenciais da gestão econômica e social. É sugerida a necessidade de os reproblematizar profundamente a partir das dificuldades suscitadas de maneira crescente no setor dito de "serviços". Deste ponto de vista, o crescimento dos serviços poderia ser a oportunidade de repensar, em geral, o modo de fabricação dos coeficientes gestionários. A utilização da noção de atividade exigia, naturalmente, uma breve investigação sobre a história deste conceito, essencialmente a partir da sua utilização ambivalente por Marx. Enfim, desenvolve-se no texto a idéia de "valores sem dimensões", na medida em que a articulação - sempre a renegociar e de maneira altamente problemática - entre valores quantificáveis e tais valores (que operam inicialmente num universo estrangeiro aos instrumentos de medida), nos parece um ponto crítico essencial da matriz da historicidade do espaço social. E nós reencontramos aí os desafios diretamente operatórios de tais interrogações conceituais: qual impacto na gestão que experimentam formas renovadas de construção de coeficientes econômicos, ao considerar essas "negociações complexas de eficácia-eficiência"?2

Palavras-chave atividade de trabalho; setor de serviços; gestão do trabalho.
Abstract This article deals with the relationship between a certain approach to work (as "industrious activity") and the manipulation of the essential coefficients of economic and social management. We suggest that there is a need to equate these two things more deeply because of the difficulties that are increasingly appearing in the so-called "service sector". From this point of view, the growth of services could be an opportunity to generally rethink the way management coefficients are designed. Clearly, in order to make use of the notion of activity it will be necessary to carry out a brief investigation of the history of this concept, particularly after its ambivalent use by Marx. Finally, in the text, we expand the idea of "values without dimensions" in so far as the articulation - always able to be renegotiated and in a very problematic way - between quantifiable values and the so called values without dimensions (that operate initially in a universe alien to measurement instruments) seems to us an essential and critical point in the matrix of historicity in the social space. And there we find once more the operational challenges of these conceptual questions: what impact will they have on the type of management that experiments with new ways of building economic coefficients, as it considers these "complex negotiations of efficacy-efficiency"?

Key words work activity; service sector; work management. 


\section{É possível mensurar o trabalho sem defini-lo?}

A conjuntura obriga, o que é positivo, a que nos interroguemos sobre a consistência e os limites do conceito de trabalho. Existem várias vias de acesso a essa questão, dentre as quais a mais crítica hoje é aquela pressuposta pela distinção entre 'trabalho' vs 'não trabalho'. Mas, seja qual for a via de acesso, não escapamos a um vaivém entre preocupações muito concretas e à redescoberta das dimensões enigmáticas, que suprimem as divisões, da atividade industriosa. Queremos aqui indicar como a necessidade de reflexão sobre a questão da eficicácia nos serviços é uma via de acesso bem pertinente, na exigência desse vaivém 3 .

O crescimento dos 'serviços' na população ativa, as políticas públicas em busca de racionalização das escolhas orçamentárias, as pesquisas de 'saída de crise' e de setores econômicos beneficiários conduziram a delimitar mais de perto o problema da mensuração dos meios e recursos investidos nesses campos de atividade. Ora, para além da dificuldade de definir os 'serviços', essa preocupação de dispor de instrumentos de mensuração, de 'coeficientes', vê-se confrontada com a extrema dificuldade de apreender o próprio conteúdo do que é preciso medir ou avaliar (Jacot, 1990)4 (os inputs e os outputs, dizem os economistas). Através da questão da eficácia dos serviços, voltamos a uma questão, já aventada há uma década, sobre a dificuldade de reencontrar uma unidade, uma consistência nas formas atuais do trabalho humano; como se a análise dos serviços aumentasse uma incapacidade crescente de ligar nossas manipulações intelectuais do conceito e sua(s) realidade(s) concreta(s). Em face do declínio das formas de trabalho imediato, da diversificação das situações e dos estatutos de atividade, das novas geografias territoriais e institucionais das empresas, da proliferação dos processos e procedimentos ditos 'imateriais', da proliferação das linguagens e obrigações de comunicação, a expressão dominante poderia ser que o trabalho como forma tradicional de uso da força de trabalho (incluindo maciçamente o corpo, a execução, a sujeição aos horizontes limitados ) 'desaparece'.

Por um lado, o crescimento do desemprego estreitaria, dentro da oposição 'trabalho vs não-trabalho', os vínculos de definição entre trabalho e emprego; mas, por outro lado, esse trabalho se tornaria uma concha vazia do ponto de vista da atividade, configurando-se como significação - para aquele que 'trabalha' - unicamente o fato de estar inscrito em um lugar, num sistema de empregados. Isto, a nosso ver, é um ponto de partida pobre demais, portador de efeitos eventualmente negativos, em toda iniciativa política e civil contra as partilhas e exclusões ligadas ao desemprego. Paradoxo do pensamento atual acerca do trabalho: polarizado, por um lado, e entendemos bem por quê, sobre aquilo que faz a ligação todas as suas ocorrên- 
cias concretas, mas que é exterior à sua esfera (a contrapartida monetária, o acesso à esfera do consumo autônomo e, por meio desses dois elementos, a superação do limite em direção a uma 'verdadeira cidadania'); mas essa polarização é contemporânea a outro pólo - sem verdadeiro processo dialético entre eles - o de uma incapacidade de definir o que pode fazer ligações, do ponto de vista dos usos industriosos, entre os diversos 'empregados'.

Assim, entendemos que a maneira como vamos tentar responder à interrogação - se existe comensurabilidade ou não entre o trabalho na produção de bens e o trabalho no fornecimento dos serviços - reencontra essa perplexidade histórica, epistemológica, filosófica: existem 'mutações' na esfera do trabalho, deslocamentos fundamentais, um esvaecimento mesmo do trabalho? Ou, mais precisamente, reencontramos essa perplexidade a partir da questão dos 'coeficientes' nesses campos profissionais em que é difícil definir no numerador 'produtos' 5 (ao contrário dos setores diretamente produtores de bens tangíveis, como parece à primeira vista), em relação às entidades humanas e sociais bem circunscritas no denominador, em limites temporais mais ou menos limitados.

\section{O trabalho, entre o antropológico e o histórico}

A problemática que estamos desenvolvendo aqui sempre foi particularmente sensível às características gerais da atividade humana. Ao mesmo tempo, e a não ser caindo na pior abstração, uma iniciativa como essa deve interrogar-se sobre as dimensões históricas e sociais que sobredeterminam, reconfiguram, essas características gerais. Da mesma forma, ela deve tentar apreender de que maneira as formas específicas de atividade - aqui, por exemplo, produção/serviços - levam a ponderar, alterar, transformar em tal direção esses elementos de relativa generalidade. Dizendo de outra forma, não há interrogação antropológica sobre a questão que não seja, ao mesmo tempo, uma pesquisa sobre os processos históricos - o histórico sendo aqui processo de diferenciação, de singularização. Parece-nos que é no contexto desse tipo de abordagem da atividade industriosa que podemos apreciar melhor o que há de tendenciosamente novo, no que se pôde chamar de 'mutações do trabalho', que há uns 15 anos vêm afetando o modo capitalista de produzir, reconfigurando exigências ou características que lhe são próprias ou de natureza mais profunda ainda; e apreciar, igualmente, em que sentido, produção e serviços, desenvolvem características específicas.

Parece-nos que é com a mesma preocupação de comensurabilidade e incomensurabilidade relativas que devem ser pensadas as oposições clássicas entre 'trabalho' e 'extra-trabalho' e, é claro, 'trabalho' e 'não-trabalho'. Sem essa preocupação corre-se um forte risco de mutilar os dois termos da opo- 
sição. Existe aí, aparentemente, um delicado problema de conceituação: é preciso saber pensar, ao mesmo tempo, as dinâmicas imemoriais muito profundas que continuam a produzir seus efeitos em nós, a impulsionar circulações entre esferas que a prática social separa, e configurações engendradas por invenções e acontecimentos sócio-históricos, com graus de eficácia muito variáveis - que só uma abordagem clínica pode avaliar —, nas quais as primeiras tomam forma, de acordo com desenvolvimentos contraditórios originais e específicos. Como, sem esse distanciamento histórico, antropológico ou filosófico, diagnosticar constatações, males, desafios ('crises do trabalho', superação ou manutenção da 'centralidade do trabalho', segmentação do 'trabalho' ...) relativos às transformações de uma realidade que avaliamos mal onde começa, onde acaba; da qual distinguimos mal as condições em seus limites, conceituais ou históricos, em cada um de nós e para o gênero humano?

Como, por exemplo, contornar essa questão dos três diferentes limiares, a partir dos quais, com boas razões, sempre é possível afirmar que é ali que começa o trabalho? Seja o homo habilis, há 2,5 milhões de anos, com a fabricação em série de ferramentas pensadas em função de fins, no eixo da apropriação melhorada dos recursos naturais, transformando, para essa nova espécie biológica, a significação e as exigências do que é viver; seja o neolítico, com a invenção de sociedades que organizavam ritmos sociais em torno dos ciclos da produção agrícola e da criação de animais; seja a emergência do capitalismo a instituir a forma-salário, delimitando assim um tempo de trabalho exteriormente normatizado, remunerado e separado das outras esferas e temporalidades da vida social.

Cada um desses diferentes limiares transformou profundamente a própria noção de trabalho - trabalho esse que se diz hoje estar mudando. Pensar essas mudanças sem levar em conta em que esses acontecimentos históricos determinaram estruturalmente o trabalho é argumentar sobre o abstrato. Ao mesmo tempo, estamos convictos de que existem elementos fundamentais de toda atividade, que atravessam esses limiares 6 (Schwartz, 1988; 1993a; 1993-1994; 1994; 1995, 2000a), que é preciso articular estas dimensões antropológicas e estas dimensões históricas para localizar o que muda, o que provoca crise no trabalho. O trabalho, na verdade, nunca começou e, ao mesmo tempo, rejuvenesce sem cessar.

\section{Da atividade}

A esse respeito, a dificuldade, até mesmo a impossibilidade de abster-se do conceito de 'atividade' poderia demonstrar a necessidade de pensar as comensurabilidades industriosas e suas incomensurabilidades relativas, a um 
só tempo diacronicamente - ver o que acabamos de dizer a propósito dos diversos 'nascimentos' do trabalho - e sincronicamente - entre as diversas esferas da vida social.

No entanto, esse conceito de atividade é gauche, impreciso, estigma de um pensamento em busca de seu rigor. Labica (1987), em sua pequena obra sobre As teses sobre Feuerbach (Marx, 1987), mostrou precisamente o papel intermediário da Tätigkeit, da atividade, na reviravolta filosófica de Marx. "Por estar contraposta ao objeto, à realidade, à sensibilidade, a atividade, como vimos, tomou-lhes as conotações. Ela foi sucessivamente capturando, para deles fazer seus epítetos, o sensível (sinnliche Tätigkeit), o real (wirkliche T.) e o objetivo (gegenständliche T.)"7. Com a especificação da atividade como "revolucionária", "praticamente crítica", chegamos exatamente ao "ponto de não retorno da crítica operada contra a filosofia"8.

Mas as especificações logo vão se revelar com melhor performance que o próprio conceito. O idealismo pode assumir a atividade como seu recurso, como se caracterizasse o próprio funcionamento do espírito ou da razão. Por isso, uma vez cumprida a sua 'missão' de primeiro ponto de resistência, a atividade, conceito ambivalente demais, "devia ceder o lugar à prática" (antes que esta, na tese 11, também ceda o lugar à "revolução") 9 .

Porém, não se pode dispensar assim a atividade, nem se desfazer com tanta facilidade de suas propriedades equívocas de transversabilidade e de circulação. Lembremos, por exemplo, que Max Weber (1971), no início de Economie et Société, propõe como objeto à sociologia "compreender por interpretação" a atividade social, e que ele define por "atividade" (aqui Handeln) "um comportamento humano (...), quando e na medida em que o agente ou os agentes lhe comunicam um sentido subjetivo"10. A psicologia soviética fundou importantes trabalhos sobre esse conceito vago (Vygotsky e Léontiev, notadamente em Activité, conscience, personnalitél1).

Parece-nos importante indicar que o recurso ao conceito de 'atividade' é abundante na linguagem e nos textos dos profissionais da análise do trabalho, sob as suas formas mais atuais. É um dos traços característicos da ergonomia francófona reivindicar para as situações a serem estudadas o 'ponto de vista da atividade' (Wisner, 1991). Por oposição ao fornecimento de meios sobre o funcionamento do homem como elemento de um sistema em operação, a referência à atividade quer remeter à esfera das múltiplas microgestões inteligentes da situação, às tomadas de referências sintéticas, ao tratamento das variabilidades, à hierarquização dos gestos e dos atos, às construções de trocas com a vizinhança humana, num vaivém constante entre os horizontes mais próximos e os horizontes mais afastados do ato de trabalho estudado. Os lingüistas, notadamente aqueles que fazem da análise das situações de trabalho seu objeto privilegiado de estudo, falam de 'atividades linguageiras' ou 'comunicacionais', de 'práticas linguageiras', sem 
mesmo falar de todas as formas de interação ao mesmo tempo linguageiras e sociais12 ( Faïta, 1989).

O uso do conceito de atividade, longe de ser apenas um resíduo antigo, a ser hoje especificado por quadros sociais mais exigentes e/ou limitantes, parece, ao contrário, estar voltando com força precisamente no caso dos serviços - em que o tamanho da dimensão 'prestação' reintroduz, bem ou mal, inclusive ao nível das tentativas mais oficiais de nomenclatura - as características de transversabilidade vaga próprias a esse conceito. Jean Gadrey, um dos melhores especialistas em economia dos serviços na França, constatava, num artigo de 1991, a impossibilidade de reduzir claramente o trabalho assalariado em numerosos serviços a um produto social caracterizado, circunscrito e mensurável. É exatamente por isso que as estatísticas nacionais relativas a atividades de serviços - tão importantes para os conselhos das empresas quanto para a educação, a saúde, os serviços associativos, as administrações públicas — retornam sempre, mais ou menos, a definir seu 'produto' a partir do trabalho fornecido (por vezes batizado de 'atividade').

Essa ambigüidade nos parece bem ilustrada pelo texto de um coletivo de ergonomistas, texto esse profundo, ao mesmo tempo que discutível: "L'activité de travail: une forme d'activité humaine" (Guérin et al., 1991). E o que é a atividade humana, na qual se inclui o trabalho? "Em primeira aproximação, a atividade se opõe à inércia", é "o conjunto dos fenômenos (...) que caracterizam o ser vivo". E, com efeito, a atividade de trabalho pode não se sentir comprometida profundamente por essa definição? Essa simples definição - de oposição à inércia - já não acarreta conseqüências ergonômicas, sociais, axiológicas quanto ao governo humano do trabalho? Não é por nada que Canguilhem, em 1966, confessava ainda correr o risco de "fundar a significação fundamental do normal por uma análise filosófica da vida, entendida como atividade de oposição à inércia e à indiferença". Recenseamos as poucas ocorrências breves e luminosas em que sua definição da vida, como atividade de oposição à inércia, era extrapolada num meio humano de trabalho (Canguilhem, 1947; Schwartz, 1992)13 em que ela aparecia como o fundamento da resistência operária ao taylorismo e, para além, a toda situação de heterodeterminação das normas industriosas.

Ao mesmo tempo, o texto dos ergonomistas lembra que "de maneira corrente, a atividade de trabalho é nitidamente distinta da atividade humana em geral" (op. cit., p. 45-46)14. E o que vem depois mostra bem que esses ergonomistas assumem a nítida especificidade do trabalho em relação à atividade, como atividade socialmente finalizada, melhor até, como 'atividade imposta'. Num certo sentido, é a experiência que eles têm de intervenções em empresa que os leva a isso sem hesitação. Mas essa especificação levanta um duplo problema, e eles formulam muito bem o primeiro: com base no que foi apontado, a dona de casa, o estudante, o desempregado, o biscatei- 
ro não 'trabalham'. Não é excessivo separar a tal ponto essas configurações diferenciadas de uso de si?

Por outro lado, definir o trabalho pela imposição não é anular em grande parte a inclusão do trabalho na atividade vital concebida como oposição à inércia e à indiferença (do meio em relação às exigências do que significa viver para o ser em questão)? Essa inclusão na atividade vital, sem apagar a exigência específica a todo trabalho social (sempre uso de si por 'outros'), não deixava entender que sempre havia também necessidade e reivindicação, de uma forma até muito enfraquecida, às vezes imperceptível, de uso de si 'por si'? De uma tentativa de renormalização do meio de trabalho segundo suas próprias condições?

Se voltarmos à definição do produto dos serviços pelas 'atividades', evocada por Gadrey (1991), o problema vem em parte do fato de que as finalidades impostas, a exigência, a sanção social parecem, sob esse vocábulo 'atividade', se desfazer. O vocábulo 'atividade' não faz mais, nitidamente, a distinção com os serviços ou as prestações múltiplas de que a vida cotidiana, fora do tempo remunerado, é o caldeirão e o espaço. Mas, justamente, isso não é um indício de que é preciso pensar, ao mesmo tempo, tanto as especificidades não redutíveis entre os espaços e os tipos de exigências, quanto as circulações em todos os sentidos (para retomar um termo utilizado anteriormente) entre os diferentes 'usos de si' nas diferentes esferas, tornados possíveis por sua inclusão no conceito geral de atividade15? Desse ponto de vista, datar o 'nascimento' do trabalho quando da emergência do regime salarial é cortar suas comensurabilidades - mais ou menos frouxas, mais ou menos estreitas - com as outras formas da atividade humana, por exemplo, com as atividades tradicionalmente assumidas pelas mulheres na família ou no grupo social, e cujas raízes remete a outras épocas 16 . Ao ocultarmos aquilo em que essas atividades têm em parte a 'dimensão' de um trabalho, tornamos difícil a inteligibilidade do reinvestimento possível do trabalho doméstico no trabalho assalariado, o segundo alimentando-se nos patrimônios inventivos e de experiência do primeiro (Matheron, 1994).

Em suma, a atividade, conceito turvo e transversal, não poderia ser facilmente dispensada. Entre uma ação humana qualquer - trabalho para si, trabalho doméstico, atividade lúdica, esportiva - e um trabalho economicamente caracterizado, não há descontinuidade absoluta: ambos são comensuráveis a uma experiência, a de uma negociação problemática entre normas antecedentes e as normas de sujeitos singulares, sempre a serem redefinidas aqui e agora. O que torna possível, entre o tempo de trabalho assalariado e o tempo 'privado', a circulação de valores e de patrimônios. Mas dizer isso não pode conduzir a uma preguiça intelectual, a uma desmobilização cívica e política que se absteriam de conceituar as especificidades e que disso se prevaleceriam para retirar qualquer virulência do fato do desemprego. In- 
sistir no engajamento institucional representado por um emprego (por oposição às simples atividades privadas, até mesmo associativas) é valorizar, com toda razão, o trabalho como encontro possível da modernidade, da diversidade, das solidariedades conquistadas, como elaboração de engenhosidades coletivas confrontadas com exigências, urgências, escolhas; essa dimensão do trabalho é de natureza a solicitar, mais profundamente que qualquer outro uso de si mesmo, a apropriação do meio de vida como seu, histórico, humano, pelo menos nas sociedades como as nossas. Não se pode mitificar o emprego ou o trabalho assalariado. Mas não se podem subestimar os efeitos de devastação social e pessoal da exclusão dessa matriz de acesso à experiência cívica e histórica.

Ou, para dizê-lo ainda de outro modo: a análise das atividades, no sentido mais amplo evocado anteriormente a propósito da concepção dos ergonomistas, é, em um certo sentido, mais rica que a simples análise do trabalho; pois ela se interessa por todos os 'usos de si', transcendendo todos os limites sociais, temporais, institucionais; apta, por aí, a pensar as circulações e reinvestimentos entre estes. Desse ponto de vista, a análise do trabalho assalariado parece mais pobre, na medida em que só certos segmentos da vida humana estão em questão e que a heterodeterminação das normas (variável conforme as épocas, as formas de governo do trabalho) restringe a esfera das conquistas inventivas. Porém, muito mais rica num outro sentido, pois, a não ser que seja mutilante, cega, a análise do trabalho (assalariado ou de forma mais geral amarrado à troca mercantil) vai necessariamente encontrar, infiltrados de forma variável, na configuração que ela estuda, os efeitos - sempre ressingularizados e móveis - das conjunturas e das determinações históricas. Visamos por aí às relações sociais de produção, às leis dominantes da gestão dos homens e das coisas, às formas de antagonismos e processos contraditórios que se geram no seio delas.

Última observação a respeito da atividade. Essa fecunda ambigüidade do conceito nos parece ser encontrada em Marx, quando ele define o processo de trabalho. O primeiro elemento, 'trabalho propriamente dito', é apresentado como Zweckmässige Tätigkeit, atividade orientada por um objetivo. No trabalho, comenta ele, (Marx, 1950), o homem "realiza ao mesmo tempo seu próprio objetivo do qual tem consciência, objetivo que determina como uma lei seu modo de ação, e ao qual deve subordinar a sua

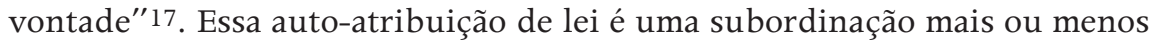
tensa conforme a força relativa da exigência (objeto e modo de execução) afaste ou não o indivíduo de um 'livre jogo das forças corporais e intelectuais'.

Impossível escapar à sofisticação do 'objetivo' que pode ser, em graus diversos, e diversamente congruentes ou contraditórios, o do trabalhador - na medida em que é único e claro para ele mesmo - e o das diversas en- 
tidades sociais no seio das quais esse processo de trabalho se desdobra. A simples menção do 'objetivo' obriga, portanto, a sair da definição neutra e a-histórica para imergir a Tätigkeit em figuras históricas concretas. Ao mesmo tempo, essa sofisticação do objetivo não anula em nada, muito pelo contrário, a exigência de uma enigmática instrumentação de um corpo inteligente (cf. em surdina, a referência kantiana ao 'livre jogo das faculdades'), requerida para operar em toda situação de transformação - inclusive a mais intelectual —, em toda situação histórica, entre os dois pólos da exigência in-'atraente' e do 'livre jogo'.

Essa continuidade em nós, indo da instrumentação enigmática do corpo próprio ao confronto no campo da cultura, dos valores e das contradições - através do uso industrioso de si — é o inesgotável apelo a pensar o trabalho humano18. Quando Marx define o processo de trabalho "fora de toda chancela particular", ele exprime bem seu caráter abstrato enquanto não for subsumido sob formas históricas cujas características principais é conveniente, em tendência, conceitualizar. Mas essa atividade, em sua dimensão híbrida, nem por isso está abolida com esta ou aquela 'característica particular'; ela coloca suas exigências através de todas as figuras que a humanidade industriosa produziu e produzirá19 (Schwartz, 1988).

\section{Volta aos serviços: comensurabilidades e especificações}

De passagem, evocamos alusivamente alguns desses elementos transversais que nos parecem caracterizar a atividade no sentido mais abrangente do termo. Assim aconteceria com o que se poderia chamar de a dialética do programa 20 e da atividade, ou das normas antecedentes e das normas individualizadas, ou ainda, mais simplesmente, dos dois registros: o primeiro indicaria o que pode ser antecipado e explicitado no seio de um patrimônio socialmente partilhado e transmitido (métodos), a partir de elementos de relativa generalidade, sobre os quais podem, por essa mesma razão, trabalhar conceitos e definir programas e prescrições, termos que remetem, ao mesmo tempo, às circunstâncias sociais em que esses elementos de patrimônio se formam, se deformam e se reformam. Esse campo da antecipação das situações de atividade também seria, portanto, o da linguagem acabada, já que esta pode neutralizar os parâmetros singulares de um processo que se desenrola, por outra via, sempre no espaço e no tempo. O segundo remeteria ao que é da ordem da gestão do singular, que registra, na atividade cotidiana de trabalho, o efeito da dimensão histórica de toda prática, a não repetibilidade perfeita das situações humanas, sociais, produtivas.

A generalidade dessa dialética, inclusive nas organizações tayloristas, autorizaria a caracterizar todo trabalho como o lugar de uma dramática sin- 
gular, em que cada protagonista negociaria a articulação dos usos de si por 'outros' e 'por si'. A mesma generalidade dessa dialética leva igualmente a pesquisas, em todo caso, sobre a recomposição coletiva das tarefas e das obras, jamais estritamente representável nos organogramas preexistentes.

No que diz respeito, desta vez, às tendências, elas também gerais, das mudanças atuais, evocamos o declínio do trabalho imediato, a deriva da linguagem - a ser tomada cum grano salis, de 'trabalhar para gerir'. Gerir, devendo ser entendido num sentido complexo, que articule uma dimensão ainda nitidamente profissional ('gerir imprevistos' próprios à atividade considerada); uma dimensão mais econômica (disseminação problemática das condutas de gestão e de contabilidade conforme escalões mais descentralizados); uma dimensão intersubjetiva (a equipe) e pessoal, tal que os ingredientes precedentes possam encontrar as vias de uma instrumentação do si em condições subjetivamente aceitáveis.

Vamos nos permitir remeter, quanto a este ponto e se necessário a escritos anteriores ${ }^{21}$ (Schwartz, 1993b). O que nos parece interessante é tentar pensar a introdução desses elementos transversais na história, no seguinte duplo sentido: ir da conceituação das especificações da história aos efeitos sobre as figuras concretas da atividade; e, reciprocamente, o caráter universal dos elementos transversais permite precisar o grau de validade dos recortes conceituais, obrigando a pensar sempre no modo tendencial22. E, em vez de estudar como a forma salarial em geral (e suas contradições próprias) configura especificamente as dinâmicas da 'atividade' — o que tentamos fazer depois e com muitas outras - é pensar aqui o grau de especificação tendencial induzido pela forma 'serviço' em relação às atividades produtivas. O eixo da investigação sendo, como dissemos mais acima, a abordagem diferencial da medida da eficácia do trabalho.

Uma vez admitido que entre produção e serviços o ponto de vista da atividade industriosa torna comensuráveis, sob certos aspectos, todas as situações, e que certas formas de abordagem, certos conceitos têm valor operatório geral e questionam toda construção de coeficientes de eficiência e de performance independentemente dos setores de atividade, chegamos então ao fato de que essa dimensão 'transversal' aí se exerce em condições diversificadas: nos serviços, a atividade industriosa tende a se esgotar em seu próprio desdobramento, sem a mediação ou com a mediação atenuada de um output incerto.

\section{'Trabalhar, gerir-se'}

O enorme campo de problemas assinalado pela deriva terminológica 'trabalhar'/'gerir' encontra em certos desenvolvimentos dos serviços tal profun- 
didade que só ela justificaria, a nosso ver, a passagem por esse tipo de atividade para qualquer especulação relativa ao trabalho.

O fato que a pré-concepção do bem tangível e de seus processos de fabricação por outros libera em parte os produtores diretos de reavaliações permanentes dos fins imediatos de sua atividade; o resultado, julgado pelo produto, oferece características bem identificáveis, ao contrário da avaliação do resultado de numerosas prestações de serviço; ele volta mais defasado, desigual, para os produtores: qualidade e produtividade não têm uma forma virulenta de sanção no instante (ao contrário, por exemplo, das experiências de 'face a face') e passam pela mediação de processos cujos protagonistas são numerosos, disseminados e associados por vínculos em geral difusos (quem é responsável pela não-qualidade na produção automobilística?). Quanto menos a ação e suas exigências imediatas podem ser antecipadas e parcialmente reguladas por um output delimitado, mais a atividade de trabalho volta para o agente e requer dele esse ajustamento sempre problemático das dimensões heterogêneas que evocamos sob o termo 'gerir'. E mais algo como um 'gerirse' coloca problema numa síntese de capacidades diferentes a serem implementadas, no ordenamento das prioridades, nas escolhas a serem feitas, que também são, insidiosamente, maneiras de se escolher.

Vamos ilustrar esse vínculo entre gestão de uma situação eminentemente variável e multidimensional e gestão de si mesmo com o caso do agente comercial de trem (ACT, o 'controlador') estudado por Daniel Faïta e Sylvie Niero (1991)23. A simples acolhida e o olhar vago na plataforma de embarque lhe permitem "acumular as observações prévias sobre o comportamento dos viajantes mais notáveis" 24 . Trata-se de antecipar tipos de problemas suscetíveis de encontrar pondo em conexão sua experiência da clientela, sua capacidade de análise dos comportamentos, as circunstâncias particulares do momento, a regulamentação e os problemas que ela coloca hic et nunc.

A 'relação de serviço', por se exercer em contato com indivíduos singulares e com exigências ou regras institucionais, requer uma gestão desse ponto de encontro sempre a modular (a aplicação mecânica de uma regra é 'ingerível', sobretudo no contexto público de um vagão, uma vez que o ACT está só num meio suscetível de rapidamente tornar-se hostil a ele) e que se volta para o agente porque ele tem de inventar essas modulações a partir de seus recursos pessoais como ser humano configurado e dotado desta ou daquela maneira particular. Assim, seu diálogo com os usuários em situação irregular faz um vaivém incessante entre sua investigação implícita sobre a boa ou má fé de seus interlocutores e a gestão pessoal de seus próprios recursos inventivos. Conforme o avanço desse processo, "o ACT modifica o gênero dominante do diálogo, (...) que traduz a colocação em prática de técnicas de reconhecimento e de gestão das situações". Esse vaivém sem escapatória entre as normas institucionais heterodeterminadas, a singularidade do 
encontro e o trabalho subjetivo de 'autogestão' da situação põe em questão o agente até em suas disposições posturais. "Esse balanceamento entre as exigências da função e as regras que a regem, a emergência do sujeito através das escolhas improvisadas traduzem-se por visíveis tentativas hesitantes, guiadas pelo imperativo de salvar as aparências, conceito perfeitamente adequado a esse gênero de situações".

Em relação à simples análise objetivista da relação de serviço, esta análise do 'trabalhar, gerir' parece-nos importante, na medida em que insiste na heterogeneidade das dimensões implicadas, no engajamento subjetivo necessário do prestador em relação a campos onde há escolhas a serem feitas. É verdade que essas escolhas se encarnam em microssituações, mas remetem, ao mesmo tempo, a horizontes sociais mais amplos, e a eficácia da relação de serviço não pode, de modo algum, ser analisada sem que se levem em conta essas circulações implicadas em todo 'trabalhar-gerir' e que achamos aqui particularmente cruciais. O ACT deve, por exemplo, gerir em si mesmo essa dupla função mais ou menos contraditória de agente 'repressivo e comercial'. A avaliação do viajante 'antes mesmo da avaliação de seu bilhete' é uma escolha implícita, que remete a uma comensurabilidade social e humana dos dois protagonistas e dá ao 'comercial', entendido num sentido social amplo, uma certa prioridade em relação ao repressivo. 'É com certeza aí que ocorre em cheio a tensão entre a experiência adquirida e os imperativos da função definida no sentido da melhor definição (se possível) do serviço a ser prestado'.

'Trabalhar, gerir' quer dizer precisamente aqui que não se pode neutralizar o espaço das escolhas, conscientes ou informalizadas, a serem feitas. Os argumentos codificados, os segmentos de trocas estereotipadas têm seus limites (ainda que haja tentativas recorrentes de codificar, por exemplo, a informação ou a venda por telefone). Há uma partitura que pedimos para tocar: à qualidade da execução, acrescentam-se as fases variáveis de improvisação. Assim, é preciso 'voltar à cena' diante de um alguém que é um 'cliente', sem dúvida, mas que também é ao mesmo tempo 'usuário' e por aí também 'semelhante' ao agente, pois que ele, alternadamente, conforme as circunstâncias de sua vida, é prestador ou beneficiário de um serviço. A partitura a ser tocada não pode neutralizar a imersão social. O que é válido para toda atividade humana, já que essa dimensão de 'gestão' da atividade nunca esteve ausente. Isso incrementa o desafio a qualquer racionalização e medida do trabalho quando o resultado está por inteiro na partitura.

Quanto à sanção defasada e difusa da produtividade e da qualidade no caso da produção de bens, poderíamos ser levados a acreditar que a prestação de serviço apóia-se, no que se refere à sua performance, em protagonistas bem identificados. Aliás, é o que pode deixar supor a análise da relação de serviço em que é mesmo no agente em 'face a face' e em interação que pa- 
rece se apoiar toda a qualidade da operação. Mas o exemplo do controlador ilustra, ao contrário, que "o agente fisicamente presente no momento e no local da prestação encarna literalmente a empresa inteira e concentra todas as expectativas em matéria de serviço, sobretudo quando a qualidade deste tende a se afastar da representação ideal mantida por quem solicita" (ibid., p. 1). Com certeza, há elementos da performance que têm muito a ver com a singularidade da pessoa, como há pouco lembramos; mas, ao mesmo tempo, esta deve jogar com a performance global da empresa como recurso hic et nunc mais ou menos vantajoso para gerir a sua situação. Ela deve jogar também com todas as informações obtidas nas redes, formais ou informais, nas quais é inserida em virtude de sua participação na vida da empresa. E essa inserção nas redes, verdadeira para o indivíduo em face a face, é igualmente necessária e pertinente para atividades de serviço que não têm interação regular com um usuário. $\mathrm{O}$ que rapidamente evocamos mais acima sobre a organização prescrita e o coletivo real deve levar em conta certas especificidades ligadas à relação de serviço, sem que o essencial deva ser mais particularizado ainda.

\section{Uso de si e eficácia, eficácia do uso de si}

O que acaba de ser sugerido da deriva 'trabalhar, gerir' no caso específico dos serviços ilustra abundantemente o que se podem chamar as 'dramáti$\operatorname{cas}^{25}$ do uso de si'. O duplo interesse desse conceito seria primeiramente fazer remontar a implicação da relação de serviço — onde ele é muito mais legível - ao conjunto das atividades de serviço e, melhor ainda, aos setores de produção de bens padronizados em que ele era reputado sem significação26. Em segundo lugar, o interesse consiste em insistir - a partir do fato de que sempre há 'dramáticas', imanentes ao trabalho humano - , nas dialéticas do micro e do macro, nas circulações mutuamente reestruturantes entre valores sociais, valores humanos e construção passo a passo dos atos industriosos. Isto através do espaço das escolhas inevitáveis em qualquer circunstância e em conformidade com o que dissemos sobre a atividade. E, na medida em que se trata de eficácia nos serviços, essa dimensão perpetuamente deliberatória, essa interpelação dos agentes como seres sociais, não neutros em relação a patrimônios históricos, a valores discriminantes e/ou solidarizantes, pode ser ainda menos subavaliada, na medida em que está em ligação direta com as modalidades da prestação e, portanto, com a sua eficácia. Separando abusivamente as coisas, podemos identificar uma incontornável negociação de 'eficácia para as operações', ligada à dialética do programa e da atividade. Mas vemos que a isso adere organicamente uma negociação de 'eficácia para os efeitos', no sentido dos objetivos sociais li- 
gados aos efeitos esperados da prestação, e cuja harmonia espontânea não pode ser suposta entre os diversos agentes, os diversos 'usuários' e os diversos níveis hierárquicos da empresa. Aqui, 'gestão' está de fato em questão; mas uma gestão sem escolha, sem política, é uma gestão degradada ou não pode sequer ser considerada gestão 27 . A neutralidade civil (no sentido mais amplo do termo) dos agentes, não pode ser postulada, a não ser que se considere uma situação de gestão absurda.

Em sua lucidez, os economistas dos serviços viram precisamente surgir esses novos critérios de referência que quebram, segundo eles, a segurança de aplicação dos coeficientes industriais. Gadrey desenvolve todas as conseqüências a serem tiradas de uma visão do serviço como "resultado". Assim que o resultado 'atravessa' os indivíduos e os grupos, não se pode mais falar senão de 'outputs indiretos'. Nesses casos de outputs 'mediatos', em que predominam os efeitos de tipo final, a atividade dos prestadores, a coprodução com o usuário, "passamos, então, de uma lógica da produtividade a uma lógica da avaliação social" (Gadrey, 1986, p. 20). Acreditamos que essas duas lógicas sempre são simultaneamente operantes, mas diferentemente ponderadas. Isto posto, Gadrey nos parece prudente demais em relação às suas próprias teses: ali onde predomina a "lógica da avaliação social", que modo de avaliação, que dinâmica da performance pôr em prática se nem por isso queremos voltar às "velhas noções hedonistas" que fazem desaparecer a noção de produtividade sem nada pôr de sólido no lugar (ibid., p. 101, nota)? Não sem fortes razões, Gadrey afirma que a clientelização, a mercantilização do serviço, acompanhadas de sua burocratização, também poderiam ser apenas indícios de uma fase transitória, a lógica da avaliação social levando tendenciosamente a "encontrar o usuário por trás do cliente" (Gadrey, 1991, p. 22). Idéia bem estimulante; mas se o que poderíamos chamar 'o horizonte de uso', que convoca, de maneira vaga, entidades e pessoas beneficiárias em níveis muito diferentes do engajamento industrioso do assalariado, volta com força nos serviços, não será preciso, mais do que nunca, ligar os problemas de eficácia e de performance às modalidades do 'uso de si'? Reconhecer a imanência de um horizonte de uso nas atividades de serviço obriga a passar pelas dramáticas do uso de si para sondarlhes o valor econômico.

Assim, o 'si', matriz indeterminável, torna-se diretamente uma matriz de economia. Seria preciso fingir-se de surdo aos múltiplos pequenos detalhes da atividade cotidiana, tantos aparentes 'dons graciosos' dos agentes, e que são recebidos pelos beneficiários como promessas ou atualização de eficácia: o sorriso de uma vendedora, as palavras meio tranqüilizadoras, meio amáveis do fisioterapeuta acompanhando seus gestos profissionais nos doentes hospitalizados, os múltiplos e imperceptíveis comportamentos de eficácia que são igualmente decisões de ações 'microcustosas' e que resul- 
tam, portanto, de debates de si com si: "Não adianta me dizerem para faturar mais, não está de modo algum na minha ótica faturar mais; por exemplo, não vou obrigar um idoso a fazer um Plano Educativo Personalizado $(\mathrm{PEP})^{28}$, pois isso me partiria o coração. Temos de qualquer modo um certo número de conselhos a dar, logo a explicar ao cliente; não lhe pomos a faca no pescoço" ( Casolari, Garde e Roy, 1991).

Múltiplos pequenos detalhes com certeza, mas com freqüência conectados a valores fundamentais, como o de serviço público (Supiot, 1989), em circunstâncias tais que esses valores dão a energia criadora a esses microcomportamentos de eficácia. E também, tais que as condições de exercício mais ou menos difíceis, o grau de socialização e de colocação em patrimônio desses microatos, em contrapartida, afetam, para reforçá-los ou alterá-los, esses valores vindos de outra parte. O fato desses debates de 'si' com a eficácia se ligarem dialeticamente à eficácia do uso de si contribui aqui, certamente não a dispensar a economia - teremos visto bem aqui a sua pertinência - mas a desneutralizar os seus conceitos.

\section{Eficácia, eficiência: conflitos e dialética}

Provisoriamente, falamos de negociação de eficácia para as operações (olhando mais a dialética genérica do programa e da atividade) e de negociação de eficácia para os efeitos (mais orientada para resultados sociais e submetida a arbitragens de valor). Se admitirmos, como breves definições - a eficácia como grau de alcance de um objetivo, e a eficiência como economia nos insumos ou nos meios - a abordagem de eficiência, visando a minimizar os custos humanos de operações, seria aparentemente mais próxima da primeira negociação (para as operações). E a abordagem de eficácia, devendo exibir os seus objetivos, olharia antes na direção da segunda (para os efeitos). De fato, a realidade una das prestações de serviço manifesta que ela 'define', em outras palavras, que ela hierarquiza ou combina sem rodeios (em geral) essas duas exigências distintas. Nenhum ato pode ser inteligível seja como simples implementação retrabalhada das normas operatórias da empresa, do serviço, seja como determinado unicamente pela idéia de que os agentes construíram para si 'efeitos' sociais a serem satisfeitos. De uma certa maneira, ele sempre exprime o resultado de uma negociação de negociações.

Dificuldade primeira, de uma dualidade de conceitos a serem preservados, cujo cotidiano, no entanto, manifesta que eles são imanentes às modulações da atividade conforme hierarquizações, relações de dinâmicas muito complexas, variáveis e dificilmente decomponíveis. Evocaremos, para terminar, a topologia possível dessa complexidade. 
a) A eficácia e a eficiência podem ser uma e outra ou 'sem dimensão' ou 'dimensionadas'. Por analogia com o uso em física, uma eficácia sem dimensão não é suscetível de entrar num sistema de quantificação ou até numa relação. Por conseguinte, saímos da breve definição proposta acima, e é melhor falar de valores: assim, o valor 'saúde' ou a promoção do 'serviço público' ou a satisfação do usuário dos correios. Para serem operatórios numa política pública, tais conceitos sem dimensão devem poder ser detalhados, identificados através de indicadores qualitativos e de preferência quantitativos. Assim, uma política de saúde pública poderá definir seus objetivos quantitativos que correspondam ao que ela consideraria ser uma melhora no estado de saúde dos habitantes do país. É evidente que a passagem ao dimensionamento constitui uma ruptura no regime de uso do conceito e não se beneficia, portanto, de nenhuma evidência intrínseca. Pode haver socialmente pluralidade de dimensionamentos para um mesmo objetivo sem dimensão. E reciprocamente, a dificuldade de traduzir em critérios dimensionados os objetivos sem dimensão pode levar a recolocá-los em questão ou a repensá-los.

A eficiência aparece mais naturalmente sob sua forma dimensionada. A definição 'economia de insumos', relação entre outputs e inputs, sob essa forma, a inclui, contanto que possamos transformar esses dados em preço ou em volume. Em economia, pode ser seu funcionamento normal como indicador de performance, até que a proliferação de prestações não padronizadas no setor dos serviços venha fragilizar suas referências concretas. Entretanto, mesmo sem falar das sociedades não mercantis, podemos pensar, como, aliás, sugere a universalidade da dialética programa/atividade, que essa preocupação de eficiência também é um valor universal, que existe algo como uma 'produtividade genérica' na qual os humanos se reconhecem obscuramente como semelhantes, ligada à ampliação dos possíveis de gozo da vida29 (Schwartz, 1988). Teríamos, então, de conceber uma passagem análoga da eficiência genérica à eficiência dimensionada, abrindo um campo de problemas práticos, técnicos, organizacionais.

b) Em segundo lugar, além das relações de valores sem dimensão em critérios dimensionados constituintes de cada um dos dois coeficientes, a realidade prática e social tece vínculos entre eles, sob uma ou outra forma. Em teoria, a eficiência está antes subordinada a objetivos (à eficácia), dimensionados ou não: o valor 'promover a saúde pública' fazendo consenso, os objetivos dimensionados fixados, o problema é abordá-los com a mais judiciosa economia de meios. Mas este é um segundo salto que ele, tampouco, tem qualquer evidência, pois é pouco provável que haja uma única conduta para economizar nos insumos, para otimizar o alcance dos objetivos.

Por outro lado, a subordinação aparentemente lógica da eficiência à eficácia não tem na realidade essa unilateralidade. No seio de relações econô- 
micas em que o lucro é, em ampla medida, juiz da viabilidade das empresas, em que a produtividade é exigida como uma alavanca maior da rentabilidade dos capitais, em que o dinheiro como equivalente geral parece ser um objetivo em si mesmo, a eficiência, da mesma forma, pode subordinar a si a eficácia dimensionada. Sustentado pela busca implícita do lucro, o objetivo de economia nos insumos pode valer como comando incondicionado, dando lugar a toda uma série de coeficientes de eficácia. Por aí, ele pode criar um consenso parcial, muito ambíguo, mas inteiramente real com o valor 'eficiência genérica', evocado no item (a) (exemplo: zonas de convergências quanto às condições da performance industrial entre pessoas em níveis muito diferentes da hierarquia socioprofissional e muito desigualmente interessados na redistribuição do lucro).

Todas as espécies de conflitos, de dialéticas, de hierarquias entre esses dois coeficientes, sob suas duas formas, podem, portanto, estruturar as lógicas de atividade. Não se poderia subestimar um ponto crítico de tamanha concorrência - ainda que hoje muito diversificado em suas formas, que, aliás, pode às vezes atravessar os mesmos indivíduos - entre a eficácia sem dimensão, ordenada em valores de tipo humanista, planetário, e a eficiência transformada em objetivo incondicionado do trabalho, através do critério da rentabilidade (exemplo: na linha de montagem da Peugeot-Sochaux, certos operadores tentam fazer chacota da 'lei' de produtividade, expressa em número de carros/dia pelos contramestres a cada início de jornada, chamando-a de 'mordida' diária) (Clot et al., 1990).

c) Há concorrência porque esse jogo complexo não é teórico, ele remete à diversidade dos patrimônios de experiência e de vida, às relações de desigualdade e de segregação que se estabelecem nas sociedades, às configurações de poder, de hierarquia, aos graus de autonomia. Certo, a eficácia sem dimensão tem vocação para remeter a valores sobre os quais se estabelece um consenso mais ou menos universal; não há 'empresa' humana - o que é verdade no sentido próprio dessa palavra, antes de sê-lo para seu sentido mais preciso hoje - sem partilha mínima desse tipo de valores. Mas os deuses estão em luta, dizia Max Weber (1959), os valores, mal são traduzidos em objetivos, mal são dimensionados, exibem suas zonas de contradições internas. Os 'valores da empresa', objetos parciais de um acordo vago, revelam, uma vez codificados e numerados, defasagens de interpretação, conflitos até ali escondidos. E essas ocorrências remetem de volta - na complexidade — às diversificações tendenciais engendradas pelos processos sociais. Por conseguinte, para os diferentes protagonistas da situação, a negociação que resulta para cada uma das hierarquizações variáveis entre as formas da eficácia e da eficiência (a e b) deve operar-se sobre fundo determinante de uma exigência social, levando em conta a maneira como as outras partes envolvidas negociam, elas mesmas, as relações 
de compatibilidades e incompatibilidades parciais entre o conteúdo possível dessas noções.

Assim, esses dois critérios atravessam profundamente todas as lógicas de ação, mas recortam, permanentemente, terrenos de convergências ambíguas e de divergências evolutivas. Por exemplo, o objetivo de redução das despesas de saúde pode inscrever-se como uma exigência da eficiência dita acima 'incondicionada' (transportar os critérios de lucro ao hospital público, favorecer transferências sociais do público para o privado), mas pode também parecer resultar da eficiência dita 'genérica' (lutar contra o desperdício de recursos, poupar-se dos esforços e encargos inúteis, utilizar melhor os meios), da eficácia sem dimensão (cessar de desenvolver meios superdimensionados e custosos, liberar recursos sociais para a ajuda aos países em desenvolvimento...), da eficácia dimensionada (respeito pelas escolhas orçamentárias, distribuindo, a cada setor de atividade do país, uma parte dos recursos públicos não ilimitados).

No hospital, a eficácia toma sentido parcialmente diferente para a equipe de direção, os médicos, os enfermeiros e atendentes, ainda que a 'volta à saúde' seja o objetivo final sem dimensão ao qual todos se referem em graus diversos e que mantém um mínimo inteiramente real de consenso. Entendese, então, a dificuldade de gerir o conflito parcial entre as eficácias derivadas (por exemplo: para a direção, respeito ao planejamento sanitário; para a equipe de saúde, auxílio aos pacientes no cuidado de suas doenças ou deficiências) e as eficiências diferentes que uns e outros derivam desses objetivos (exemplo: as modalidades do atendimento da deficiência podem custar tempo de hospitalização contrário ao objetivo de redução do Tempo Médio de Permanência - TMP). Por conseguinte, eficácias derivadas podem parecer contradizer nos fatos a concretização do valor sem dimensão que as sustenta: embora o objetivo de redução do TMP, em certos casos, conduza a hipotecar o cuidado do paciente a ele mesmo a médio e a longo prazo, isso pode agravar os custos para a coletividade; é uma experiência, às vezes, feita pela equipe de saúde, que vê voltar doentes mais 'tratados' que 'cuidados'. Inversamente, uma multiplicação descontrolada de exames altamente técnicos pode alongar em excesso a passagem pelo hospital; daí o questionamento, por certos protagonistas, dos objetivos de eficácia dimensionados, a partir da experiência que eles têm com a ineficiência parcial dos indicadores derivados destes, e a promoção por esses protagonistas de condutas de eficiência alternativas mais ou menos formuladas, até mesmo outros valores sem dimensão. A atividade é, assim, o ponto de cruzamento de um vaivém entre o conteúdo desses dois coeficientes, num contexto social em que os diferentes parceiros, que têm a mesma vocação para colocar questões, uns aos outros, relativas às atividades profissionais e valores 'vindos de fora', não têm nem as mesmas experiências, nem as mesmas possibilidades ou po- 
deres hierárquicos para colocá-los em prática. Tensão inevitável que justifica, em contrapartida, o uso do termo 'dramática' para evocar essas negociações de eficácia.

A distribuição nos coletivos humanos dos diversos processos e resultados da negociação de eficácia/eficiência não se opera ao acaso; ela tem a ver com as grandes configurações sociais, os critérios econômicos dominantes, as definições socioprofissionais da atividade. Ao mesmo tempo, nenhum mecanismo a rege a priori; ela não é separável das situações muito concretas em que se colocam as questões de economia gestionária e exige imperativamente uma conduta clínica.

Resumiremos em três pontos essas negociações complexas de eficáciaeficiência:

1. A dramática do uso de si nos serviços tende a ordenar-se fundamentalmente em torno dessa negociação;

2. Considerações de eficácia e considerações de eficiência, na pluralidade de suas acepções e de suas hierarquizações, não podem ficar isoladas e estão dialeticamente confrontadas nessas dramáticas;

3. Ocultar essa dramática é um comportamento de ineficácia e de ineficiência em qualquer organização econômica; tendencialmente, isso é verdade nos serviços mais que em qualquer outro lugar, de tal modo ela está articulada aí com os processos e resultados da atividade.

Para concluir, apesar do uso dos conceitos de eficácia e de eficiência merecer mais amplos desenvolvimentos, esperamos ter sugerido que a mensuração do trabalho no setor de 'serviços' choca-se com 'circulações' que a tornam rebelde à sua inscrição em espaços definidos. Mas, assim fazendo, o uso dos conceitos é esclarecedor, ao tornar mais críticas as dramáticas próprias a toda atividade humana. Inversamente, essa dimensão de comensurabilidade, isoladamente, não ajuda muito a pensar qualquer forma de intervenção nas realidades presentes, nem nas modalidades próprias das tensões que as atravessam e jogam com as evoluções históricas. Impossível, então, contornar um esforço de conceituação - sempre em tendência - sobre a gênese e a diversificação das situações salariais, a constituição de esferas relativamente autônomas na vida e nas práticas industriosas, nas relações econômicas no seio dos Estados entre o público e o privado, para esclarecer as especificidades em movimento de nosso presente. 


\section{Notas}

1 Doutor em letras pela Université de Lyon II, membro do Instituto Universitário da França, Professor de Filosofia, diretor científico do Departamento de Ergologia - Análise Pluridisciplinar das Situações de Trabalho/ Universidade de Provence.

2 Este artigo consiste em uma tradução, realizada por Jussara Brito e Milton Athayde, do texto "Circulations, dramatiques, efficacités de l'ativité industrieuse", extraído da obra Le paradigme ergologique ou un métier de Philosophe (Octarès Editions, 2000, pp. 417432), que reúne textos produzidos pelo autor entre 1978 e 1999. Anteriormente, o mesmo artigo foi publicado em La crise do travail, livro organizado por J. Bidet. Paris: PUF, 1995, pp. 133-153.

3 Estamos utilizando aqui elementos da segunda parte do relatório de pesquisa L'evaluation économique à l'épreuve des services: l'activité entre efficacité et efficience, produzido pela equipe de pesquisa Analyse Pluridisciplinaire des Situations de Travail (APST), Université de Provence, concluído em junho de 1992, em seguida a uma licitação do Ministério da Pesquisa e da Tecnologia.

4 Sobre a distinção entre "mensuração"e "avaliação econômica", ver a esclarecedora explicação de Jacques Henri Jacot (1990).

5 Como, por exemplo, o campo do tratamento hospitalar, dos acolhimentos, ou informações do usuário, da gestão de uma conta-cliente, do conselho, do ensino etc.

6 Sobre essas questões, tomamos a liberdade de remeter a escritos anteriores (Expérience et connaissance du travail. Paris: Messidor, 1988; Travail et philosophie, convocations mutuelles. Toulouse: Octarès Éditions, 1994, assim como: Sur le concept du travail, colóquio PIRTTEM-CNRS, Lyon, nov.-déc 1992, Ed. de l'Université de Besançon, 1993 (reeditado em Le paradigme ergologique ou un métier de Philosophe. Toulouse: Octarés Ed.); Le travail change-t-il vraiment, Rencontres APST, out.1993, Revue de l'IRETEP, n. especial, 1993 e Revue UTINAM, dedicada aos Rencontres Sociologiques de Besançon, dez. 1993; Penser le travail et sa valeur, Projet, n. 236 (1993-1994) e La technique in Notions de Philosophie, Paris: Gallimard, Folio, 1995.

7 No original “D'être contraposée à l'objet, à la réalité, a la sensibilité, l'activité, nous, l'avons vu, s'est appropriée leurs connotations. Elle a successivement capturé, pour en faire ses épithètes, le sensible (sinnliche Tätigkeit), le réel(wirkliche T.) e l'objectif (gegenständliche T.) (Labica, 1987, p. 35) (N. T.).

8 No original "point de non-retour de la charge opérée contre la philosophie" (ibid., p. 34) (N. T.).

9 No original "devait céder la place à la pratique" (ibid., p.36) “(avant que celle-ci, dans la thèse 11 ne cède à son tour la place à la "revolution" (ibid., p. 130) (N.T.).

10 No original "um comportement humain (...), quand et pour autant que l'agent ou les agent lui communiquent um sens subjectif" (Weber, 1971, p.4) (N.T.).

11 Edition du Progrès, Moscou, 1984. A esse respeito, ver a utilização que a ele é dada na tese de Yves Clot, Le travail entre activité et subjetivité, Aix-en-Provence, 1992. 
12 Cf. Languages, n. 74, 1984, coordenado pelo saudoso Louis Guespin, Dialogue et interaction verbale e, igualmente, o n. 93, 1989, Paroles ouvrières (Cf. nesse último número, a abordagem de Daniel Faita do conceito de práticas da linguagem (p. 122).

13 Cf. Canguilhem, George. Milieux et normes de l'homme au travail, Cahiers Internationaux de Sociologie, III, 1947 e Yves Schwartz, Travail et philosophie, convocations mutuelles (op. cit.), p. 243 e nota 35.

14 No original "d'une façon courante, l'activité de travail est nettement distinguée de l'activité humaine en general" (N. T.).

15 Se o desemprego tende a esterilizar a vida daqueles que sofrem com ele durante um longo tempo (por extinção desse tipo de circulação), a anemia da circulação (invertida pelo não emprego maciço) altera o reinvestimento da experiência social nas atividades assalariadas e empobrece suas condições de eficácia.

$16 \mathrm{O}$ que se sabe da antigüidade da divisão sexual das tarefas? Houve um "matriarcado neolítico"? Por enquanto, na opinião do antropólogo Jacques Cauvin, há uma "constatação de ignorância". Cf. La question du "matriarcat préhistorique" et le rôle de la femme dans la Préhistoire (Cauvin, 1985).

17 No original "Réalise du même coup son propre but dont il a conscience, qui détermine comme loi son mode d' action, et auquel il doit subordonner sa volonté" (Marx, 1950, p.181) (N. T.).

$18 \mathrm{O}$ conceito de "despesa forçada", introduzido por Jacques Bidet, sempre nos pareceu próximo desse tipo de reflexão.

19 Sobre essa análise do processo de trabalho em Marx, tomamos a liberdade de remeter a nossa Expérience et connaissance du travail (op. cit.), § 14.7 e $\S 17.3$.

20 Expressão em desuso na obra do autor, que remete ao conceito de normas antecedentes (ao registro I). Assim o trabalho é entendido como o lugar de confrontação dialética, de polarização como em um ímã entre programa (ou registro I) e atividade (registro II) (N. T.).

${ }^{21}$ Cf. nota 6 e nossa contribuição na revista Futur Antérieur, n. 16, 1993b.

22 Sugerimos, a esse respeito, a necessidade de articular um duplo processo dialético, antropológico e histórico. [O autor usa a expressão antropológico no sentido de genérico humano e histórico no sentido de específico, singular (N. T.)].

23 Poderíamos também citar os diversos trabalhos de Christine Revuz e de Guy Jobert sobre o trabalho dos agentes da ANPE, desde 1991.

24 Para melhor entender o que será analisado, é importante ter em conta que no transporte ferroviário de passageiros na França, o controle direto do bilhete do passageiro é feito posteriormente à partida do trem. Ou seja, o passageiro deve registrar seu bilhete em uma máquina de validação na estação, entrar no vagão e ocupar um lugar (mas nada impede que ele não tenha bilhete e/ou deixe de validá-lo). Só após a partida é que o agente "con- 
trolador" fará a verificação da posse do bilhete, checando se há irregularidades (além de possuir um bilhete - que deve ter sido previamente registrado na máquina de validação na estação, antes de entrar no trem -, o passageiro deve estar no trem e horário corretos, além do tipo de vagão pertinente ao valor do bilhete) (N. T.).

25 No artigo "Os ingredientes da competência: um exercício necessário para uma questão insolúvel", publicado em Educação e Sociedade, v.19 n.65, o autor, na nota II, define dramatiques, no presente texto traduzido como dramáticas, nos seguintes termos "situação em que o indivíduo tem de fazer escolhas, ou seja, arbitrar entre valores diferentes, e, às vezes, contraditórios. Uma dramatique é portanto, o lugar de uma verdadeira micro-história, essencialmente inaparente, na qual cada um se vê na obrigação de se escolher, ao escolher orientar sua atividade de tal ou tal modo. Afirmar que a atividade de trabalho não é senão uma dramatique do uso de si significa ir de encontro à idéia de que o trabalho é, para a maioria dos trabalhadores, uma atividade simples de 'execução', que não envolve realmente sua pessoa" (N. Ed.).

26 Falando dos "valores sociais" cuja "presença latente mas indiscutível na consciência operária condiciona, em última instância, todas as atitudes de adesão e de freamento dos trabalhadores", Canguilhem (op. cit., 1947, p.124) havia notado, no interior do taylorismo, a importância econômica do que chamamos "dramática do uso de si".

27 Como costuma lembrar Claude Quin em suas obras e intervenções. Ver seu relatório L'amélioration des relations entre l'administration de l'Equipement et ses usagers, Relatório de pesquisa do Conseil Général des Ponts et Chaussées, novembro de 1993.

28 O PEP destina-se a adolescentes em dificuldades nos estudos (N. T.).

${ }^{29}$ Remetemos aqui à nossa Expérience et connaissance du travail, (op. cit.), cap. 16. 


\section{Referências}

CANGUILHEM, George. 1947. Milieux et normes de l'homme au travail. Cahiers Internationaux de Sociologie, III:120-136. .1966. Le normal et le pathologique. Paris: PUF.

CASOLARI, Gérard; GARDE, Eugène; ROY, Ghuyslaine, 1991. L'expertise Nouvelle Technologie: une pratique encore marginale. Aix-en-Provence: Mémoire DESS/ APST, Université de Provence.

CAUVIN, Jacques. 1985. La femme dans le monde méditerranéen. Lyon: Travaux de la Maison de l'Orient, 10.

CLOT, Yves.1992. Le travail entre activité et subjetivité. Thése, Aix-en-Provence: Université de Provence.

CLOT, Yves; ROCHEIX, Jean-Yves; SCHWARTZ, Yves. 1990. Les Caprices $d u$ flux: approche des mutations tecnologiques du point de vue de ceux qui les vivent - le cas du groupe automobile PSA. Paris: Edicion Matrice.

FAÏTA, Daniel. 1989. Monde du travail et pratiques langagières. Langages, 93:110123.

FAÏTA, Daniel; NIERO, Sylvie. 1991. Le travail $\mathrm{du}$ contrôleur dans les transpots ferroviaires: modernisation et profissionnalité. In: Colloque organisé par Plan Urbain, RATP et DRI. Paris, 16 e 18 de janeiro.

GADREY, Jean. 1986. Productivité et évaluation des services: la constucion sociale $d u$ produit. Lille: Universitè de Lille-1. (Relatório de pesquisa).

1991. Le service n'est pas um produit: quelques implications pour l'analyse économique et pour la gestion. Revues Politiques et Management Public, 9(1):1-24.

GUERIN, François et al. 1991. Comprendre le travail pour le transformer. Montrouge: ANACT (Agence Nationale pour l'Amélioration des Conditions de Travail).

JACOT, Jaques Henri. 1990. A propos de l'évaluation économique des systèmes intégrés de production. In: ECOSIP France. Gestion industrielle et mesure économique, Paris: Editions Economica.

LABICA, Georges.1987. Karl Marx: les thè- ses sur Feuerbach. Paris: PUF.

LÉONTIEV, Alexei. 1984. Activité, conscience, personnalité. Paris: Editions du Progrés.

MARX, Karl.1950. Le capital. Paris: Editions Sociales. 1987. Les théses sur Feuerbarch. Paris: PUF.

MATHERON, Geneviève. 1994. "Pratique(s)": un concept ambigu. Objectifs Soins, 25.

SCHWARTZ, Yves. 1988. Experiénce et connaissance du travail. Paris: Messidor/ Editions Sociales.

1992. L' evaluation économique à l'épreuve des services: l'activité entre efficacité et efficience. Aix-en-Provence: Université de Provence. (Relatório do grupo de pesquisa APST-Recherche, URA CNRS 1084).

1993a. Le travail change-t-il vraiment. In: Rencontres Analyse Pluridisciplinaire des Situations de Travail (APST). Revue de l'IRETEP, no especial (Paris). 1993b. Peut-on parler "en general" de l'activité de travail. Futur Antérieur, 16. 1993-94. Penser le travail et sa valeur. Revue Projet, 236, hiver.

1994. Travail et philosophie, convocations mutuelles. 2a. ed. Toulouse: Octarès Éditions.

1995. La technique. In: Notions de Philosophie (Kambouchner, D., org.), pp. 223-285, Paris: Gallimard. (Coleção Folio). 2000a. Le paradigme ergologique ou un métier de Philosophe. Toulouse: Octarès Éditions.

2000b. Sur le concept du travail. In: Le paradigme ergologique ou un métier de Philosophe (Schwartz, Yves), pp.283290, Toulouse: Octarès Editions.

SUPIOT, Alain. 1989. La crise de l'esprit de service public. Droit Social, (no especial):777-783.

WEBER, Max. 1959. Le savant et le politique. Paris: Plon. . 1971. Economie et société. Paris: Plon.

WISNER, Alain. 1991. La méthodologie en ergonomie: d'hier à aujourd'hui. Performances Humaines et Techniques, 50. 